\title{
Effects of bite-jumping appliances on mandibular advancement in growing rats: A radiographic study
}

\author{
Ridvan Oksayan ${ }^{1}$, Oral Sokucu ${ }^{1}$, Neslihan Ucuncu ${ }^{2}$
}

Correspondence: Dr. Ridvan Oksayan, Email: ridvan.oksayan@hotmail.com

\author{
'Department of Orthodontics, Faculty of Dentistry, \\ Gaziantep University, Gaziantep, Turkiye, \\ ${ }^{2}$ Department of Orthodontics, Faculty of Dentistry, Gazi \\ University, Ankara, Turkiye
}

\section{ABSTRACT}

Objective: The aim was to evaluate the effects of the use of mandibular advancement appliances on mandibular growth in growing rats. Materials and Methods: Twenty-four 8-week-old male Wistar albino rats were randomly divided into two experimental groups (12 rats each): Group I was a control group, and Group II was the mandibular advancement appliance group. A functional bite-jumping appliance was used in Group II to promote mandibular advancement. Anatomical changes in the condyle and mandible were evaluated by comparing radiographic results from before and after the study, with angular and linear measurements. Friedman and Mann-Whitney U-tests were used in statistical analysis. Results: According to the radiographic results, the growth of mandibles and condyles in Group II was significantly greater than with the length of the condylar process (A-B) and distance from condyle to menton (A-D) variables $(P<0.05)$. In addition, Group I showed greater mandibular base growth than did Group II $(P<0.05)$. Conclusions: We conclude that the use of an intraoral bite-jumping appliance can stimulate condylar growth and increase sagittal mandibular advancement in growing rats.

Key words: Bite-jumping appliance, mandibular advancement, rat condyle

\section{INTRODUCTION}

Skeletal Class II malocclusion as a result of mandibular deficiency is a problem commonly diagnosed in the orthodontic department. ${ }^{[1]}$ Functional appliances for the treatment of Class II malocclusion have been used since the 1930s.$^{[2]}$ Mainly, functional appliances have been divided into two groups: Fixed functional appliances and removable appliances. Functional appliance treatment among adolescent patients has the power to treat mandibular retrognathia by increasing condylar growth and mandibular advancement. Many orthodontic appliances are called "functional devices for mandibular advancement" these appliances affect the functional muscles, and also influence the glenoid fossa and mandibular condyle position. ${ }^{[3,4]}$ The orthopedic treatment of Class II malocclusions increases upward and backward condyle growth, and this mechanism has been found to have an important role in the forward movement of the mandible. Experimental animal studies have shown bone remodeling in the condyle in response to mandibular advancement. ${ }^{[5]}$

The results of many studies indicate that condyle growth and the mandible advancement can be increased in growing rats through the use of bite-jumping devices. Xiong et al. produced a mandibular protrusion with a bite-jumping appliance, and found that the length of condylar process increased significantly over a 30 day experimental period. ${ }^{[6]}$ Taira et al. reported that mandibular growth is enhanced in growing rats through mandibular advancement promoted by the use of fixed functional appliance. ${ }^{[7]}$ Rabie $e t$ al. found a significant increase in vascularization in condyle and mandibular bone growth in growing rats, through the

\footnotetext{
How to cite this article: Oksayan R, Sokucu O, Ucuncu N. Effects of bite-jumping appliances on mandibular advancement in growing rats: A radiographic study. Eur J Dent 2014;8:291-5.

Copyright @ 2014 Dental Investigations Society. DOI: $10.4103 / 1305-7456.137624$
} 
use of bite-jumping appliance. ${ }^{[8]}$ Results in mandibular morphological and condylar growth studies are typically analyzed with lateral radiography, which is commonly used to evaluate mandibular morphology changes in orthodontic patients. This radiographic method is reliable and less costly than other methods. ${ }^{[7,9,10]}$

The primary objective of this study was to investigate the effect of mandibular advancement appliance on mandibular growth in growing rats, through the use of lateral radiography.

\section{MATERIALS AND METHODS}

Experimental procedures were approved by the Inönü University Experimental Animal Ethical Committee, with a 2013/A-38 code. Twenty-four male, 8-week-old Wistar albino rats were divided randomly into two groups: Group I $(n=12)$ was the control group, and Group II $(n=12)$ was the bite-jumping appliance group [Table 1]. The rats were caged in a 12-h light-dark cycle, within a $23^{\circ} \mathrm{C}$ and ideal-humidity environment. They were fed ad libitum a soft diet, to prevent any damage to the functional bite-jumping appliances. Linear and angular anatomical parameters in mandible and condyle growth were determined with cephalometric radiography during the study period. Intramuscular injections of $80 \%$ xylazine (Rompun-Bayer, Germany) and 20\% ketamine hydrochloride (Ketalar-Eczacibaşı, Turkiye) were used as anesthesia prior to cephalometric radiography and bite-jumping appliance application.

Cephalometric radiographs of experimental animals were taken before (T0) and after (T1) the study process with the same digital machine (DX3000; Dexcowin, Seoul, South Korea). The right side of the head of each rat was placed in contact with digital phosphor plate films (Digora Imaging Plates, Size 2; Soredex, Finland). The distance between the film and the radiographic focus of the device was $10 \mathrm{~cm}$, and X-ray images were obtained $(60 \mathrm{kVp}, 1 \mathrm{~mA}$ ve $1.30 \mathrm{~s})$. The criteria for radiograph selection were that the condylar area, the posterior border of the ramus, and the lower border of the mandible all had to be clearly readable on the cephalometric radiographs, to make it possible to define mandibular and condylar landmarks. Each digital radiograph was traced with a digital tracing

\begin{tabular}{lccc}
\multicolumn{3}{l}{ Table 1: Groups and experimental protocol } \\
Groups & $\mathbf{N}$ & Bite-jumping appliance & Experimental period \\
I (control) & 12 & - & 30 days \\
II & 12 & + & 30 days \\
\hline
\end{tabular}

program (Universal Desktop Ruler, AVP Soft) by the same investigator (R.O).

\section{Definitions of landmarks}

In what follows, the most posterosuperior point of the condyle is called the A point, the midpoint of the mandibular foramen is called the B point, the most anterior point of the lingual alveolar bone is called the $C$ point, the menton is called the $\mathrm{D}$ point, the most inferior part of the lower border angular process is called the E point, and the mandibular plane is called the Mp point ${ }^{[6]}$ [Figure 1].

\section{Linear measurements}

The length of the condylar process is referred to as $\mathrm{A}-\mathrm{B}$; the mandibular length, A-C; the distance from point $\mathrm{A}$ to menton, $\mathrm{A}-\mathrm{D}$; the length of mandibular base, B-C; and the perpendicular distance from A to $\mathrm{Mp}, \mathrm{A}-\mathrm{Mp}^{[6]}$ [Figure 1].

\section{Angular measurements}

The angle of the condylar process axis to the mandibular plane is called the Stutzman angle ${ }^{[6]}$ [Figure 1].

The bite-jumping appliance used in this research is similar to that used in previous studies to improve rat mandibular incisors. ${ }^{[6,11]}$ Functional bite-jumping appliances were fitted to the mandibular incisors of rats in the experimental group and bonded to mandibular incisors with self-etching composite (Transbond Plus; 3M, Monrovia, CA, USA). This bite-jumping appliance produced $2.5-3 \mathrm{~mm}$ forward mandibular advancement in Group II [Figure 2].

\section{Statistical analysis}

A nonparametrical Friedman test and a Mann-Whitney U-test were executed to examine intra- and inter-group significant differences in angular and linear measurements [Tables 2 and 3]. SPSS for Windows (SPSS Inc., Chicago, IL, USA; Windows version 20.0) was used in statistical analysis.

\section{RESULTS}

There were statistically significant changes in mandibular morphology in the control and appliance groups within the study period. At the T1 time-point, it was found that $\mathrm{A}-\mathrm{B}, \mathrm{A}-\mathrm{D}$, and $\mathrm{B}-\mathrm{C}$ had each increased significantly $(P<0.05)$. In addition, in Group II, the A-B, A-C, and A-D parameters had increased significantly $(P<0.05)$ during the study period.

According to the Mann-Whitney U statistical test results, the growth of $\mathrm{A}-\mathrm{B}$ between $\mathrm{T} 0$ and $\mathrm{T} 1$ in 


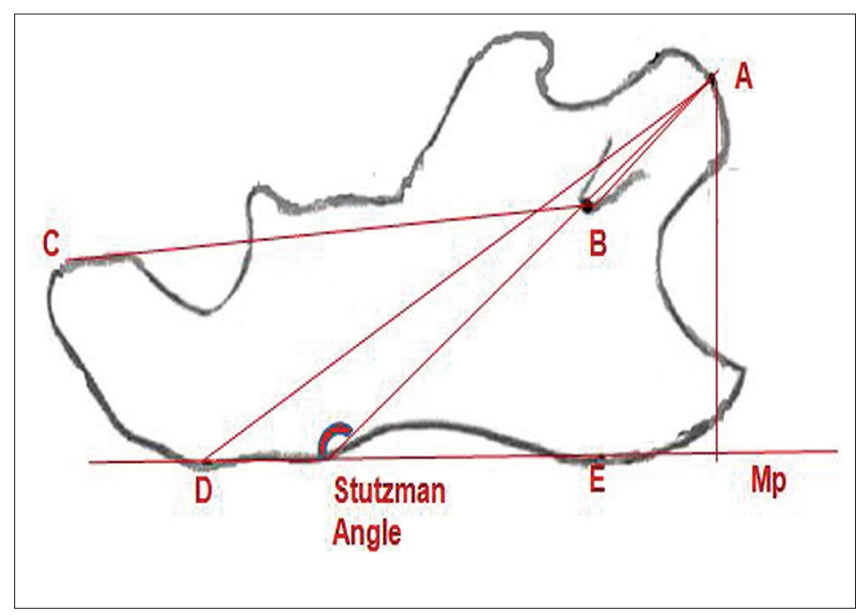

Figure 1: Skeletal landmarks, linear and angular measurements

Group II was significantly greater than that in the control group $(P<0.05)$. The dimension change in A-D at 30 days within Group II was significantly greater than that in the control group $(P<0.05)$. The growth of the B-C length in Group II during the study period was significantly lower than that in the control group $(P<0.05)$. In addittion, there were no statistically significant changes in the A-Mp or Stutzman angle parameters $(P<0.05)$.

The body weight of the experimental animals in both groups did not decline during the study period. During the study, the increase in weight in the control group was greater than that in Group II [Table 4].

\section{DISCUSSION}

The effects of skeletal Class II treatment with mandibular retrognathia depend upon the capacity of bite-jumping appliances with regard to condylar growth. Many functional bite-jumping appliances have been used to enhance condylar growth and mandibular advancement. In this experimental study, functional bite-jumping appliances were used to promote condylar changes and mandibular advancement among growing rats over a 30 days period. Due to the morphological, anatomical, and structural similarities to human condyles and mandibles, the rat model was chosen for this study. ${ }^{[5]}$

The findings of this study with respect to three parameters (A-B, A-D, and B-C) indicate that Group I showed significant mandibular and condylar growth without any external stimulus during T0-T1. This result suggests the role of condylar growth in growing rats.

Group II showed statistically significant growth with respect to three sagittal mandibular growth variables

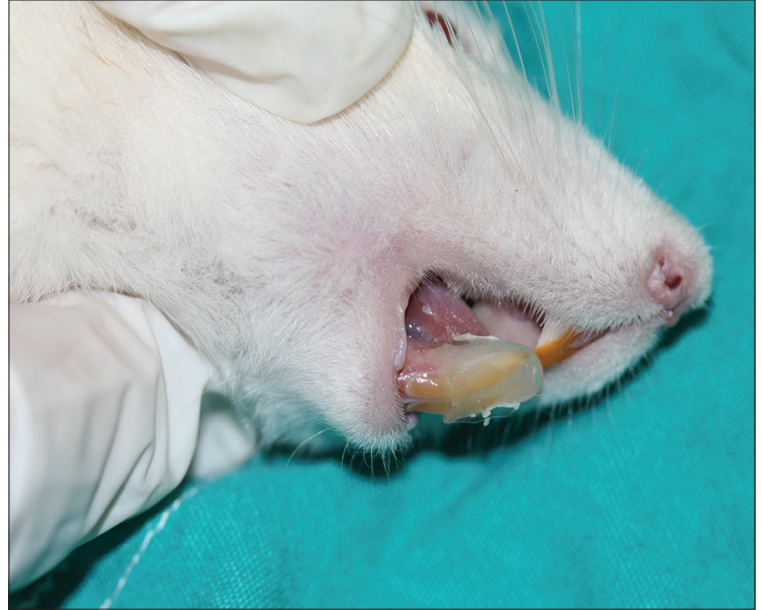

Figure 2: Bite-jumping appliance

\begin{tabular}{|c|c|c|c|c|}
\hline \multirow[t]{2}{*}{ Groups } & \multirow[t]{2}{*}{ Variables } & \multicolumn{2}{|c|}{ Mean $\pm S D$} & \multirow[t]{2}{*}{$P$ value } \\
\hline & & TO & T1 & \\
\hline \multirow[t]{6}{*}{ I (control) } & $A-B(m m)$ & $6.63 \pm 0.70$ & $6.81 \pm 0.71$ & $0.021^{*}$ \\
\hline & $\mathrm{A}-\mathrm{C}(\mathrm{mm})$ & $24.46 \pm 1.65$ & $24.63 \pm 1.20$ & 0.083 \\
\hline & $\mathrm{A}-\mathrm{D}(\mathrm{mm})$ & $22.02 \pm 1.51$ & $22.29 \pm 1.04$ & $0.021^{*}$ \\
\hline & $\mathrm{B}-\mathrm{C}(\mathrm{mm})$ & $18.90 \pm 1.45$ & $19.39 \pm 1.41$ & $0.021^{*}$ \\
\hline & A-Mp (mm) & $11.62 \pm 2.08$ & $11.77 \pm 1.66$ & 0.564 \\
\hline & Stutzman angle & $144.86 \pm 1.03$ & $145.11 \pm 0.96$ & 0.564 \\
\hline \multirow[t]{6}{*}{ II } & $\mathrm{A}-\mathrm{B}(\mathrm{mm})$ & $7.15 \pm 0.44$ & $8.19 \pm 0.61$ & $0.002^{*}$ \\
\hline & $\mathrm{A}-\mathrm{C}(\mathrm{mm})$ & $26.17 \pm 0.84$ & $27.02 \pm 0.79$ & $0.002^{*}$ \\
\hline & $\mathrm{A}-\mathrm{D}(\mathrm{mm})$ & $23.04 \pm 0.85$ & $24.23 \pm 0.83$ & $0.002^{*}$ \\
\hline & $\mathrm{B}-\mathrm{C}(\mathrm{mm})$ & $20.07 \pm 0.84$ & $20.08 \pm 0.71$ & 0.527 \\
\hline & A-Mp (mm) & $11.55 \pm 0.69$ & $11.63 \pm 0.68$ & 0.527 \\
\hline & Stutzman angle & $146.21 \pm 1.95$ & $146.90 \pm 1.21$ & 0.058 \\
\hline
\end{tabular}

\begin{tabular}{|c|c|c|c|}
\hline \multirow[t]{2}{*}{ Variables } & \multicolumn{2}{|c|}{ Mean $\pm S D$} & \multirow[t]{2}{*}{$P$} \\
\hline & $\begin{array}{c}\text { Group I } \\
\text { (control) (T1-T0) }\end{array}$ & $\begin{array}{l}\text { Group II } \\
\text { (T1-T0) }\end{array}$ & \\
\hline$A-B(m m)$ & $0.18 \pm 0.30$ & $1.04 \pm 0.48$ & $0.000^{*}$ \\
\hline $\mathrm{A}-\mathrm{C}(\mathrm{mm})$ & $0.17 \pm 0.87$ & $0.85 \pm 0.58$ & 0.080 \\
\hline$A-D(m m)$ & $0.27 \pm 0.74$ & $1.19 \pm 0.73$ & $0.011^{*}$ \\
\hline $\mathrm{B}-\mathrm{C}(\mathrm{mm})$ & $0.49 \pm 0.55$ & $0.02 \pm 0.44$ & $0.043^{*}$ \\
\hline A-Mp $(\mathrm{mm})$ & $0.15 \pm 0.55$ & $0.09 \pm 0.76$ & 0.821 \\
\hline Stutzman angle $\left({ }^{\circ}\right)$ & $0.25 \pm 2.08$ & $0.70 \pm 1.85$ & 0.628 \\
\hline
\end{tabular}

\begin{tabular}{|c|c|c|}
\hline Groups & TO (g) & T1 (g) \\
\hline I (control) & $262.75 \pm 48.69$ & $281.5 \pm 50.81$ \\
\hline II & $268.7 \pm 22.54$ & $272.1 \pm 22.27$ \\
\hline
\end{tabular}


during T0-T1. A number of studies concluded that mandibular growth was increased, and that functional bite-jumping appliances enhance mandibular growth in growing rats. ${ }^{[6,7,12]}$ Similar to our findings, Ghafari and Degroote found that continuous anterior and vertical displacement produce an acceleration of ossification and maturation. ${ }^{[11]}$

According to our experimental animal study results, the growth of the condylar process (A-B) in the bite-jumping group between $\mathrm{T} 0$ and $\mathrm{T} 1$ were significantly greater than that in the control group. Xiong et al. report increased condyle growth within their group of bite-jumping device animals. ${ }^{[6]}$ Our study results indicate that condyle growth among growing rats could be increased through the use of bite-jumping appliances over a 30 days period; these findings align with those of previous studies, as mentioned.

Although Group II showed greater mandibular length (A-C) growth than did the control group, there were no statistically significant differences between the two groups. This condition may be due to the brevity of the functional appliance treatment time-period, and also to the fact that the anatomical landmark (C point) may be affected by bite-jumping appliance therapy. Contrary to our study results, Taira et al. found there to be a significant mandibular length increase in their appliance group versus their control group. ${ }^{[7]}$ A possible reason may be that the bite-jumping appliance used in their study produced $3.5 \mathrm{~mm}$ forward and $3 \mathrm{~mm}$ downward movement.

The A-D length has been known to be an effective mandibular length. Mandibular growth in this length within the bite-jumping appliance group (between $\mathrm{T} 0$ and T1) was significantly greater than that in the control group. At the 30 days period, Taira et al. showed that functional appliances enhance the growth of this effective mandibular length parameter in rats. ${ }^{[7]}$

The greatest increase in B-C length was found within the control group. A functional bite-jumping appliance may not enhance this length, because the application area for functional devices is far from the distance between the $B$ and $C$ points. In addition to this, the $C$ point is very near the behind-mandibular incisor to which the appliance is fitted.

Within mandibular advancement research, growth in the perpendicular distance from A to Mp has typically suggested vertical growth. There were no statistically significant differences between the experimental and control groups. Charlier et al. studied the effects of mandibular functional appliance use with respect to young rat condyle, and they found that growth was more horizontal in the appliance group. ${ }^{[13]}$

Mandible advancement and condyle growth in rats has also been determined by the opening of the Stutzman angle. ${ }^{[14]}$ There were no statistically significant differences between the two groups, but the bite-jumping appliance group nonetheless showed a greater increase in the Stutzman angle than did the control group.

The limitations of this study include the absence of histological evaluation of condylar cartilage growth, and also the relatively short experimental time of 30 days.

\section{CONCLUSIONS}

Our experimental study results indicate that the mandibular advancement promoted through the use of a functional appliance increases mandibular and condylar growth in rats. Furthermore, the use of a bite-jumping appliance does not affect the vertical dimension of the mandible. Further investigations are suggested to evaluate the effects of bite-jumping appliances on mandibular morphological changes over a longer time-horizon and with a larger study sample.

\section{ACKNOWLEDGMENTS}

This study was supported by the Scientific and Technological Research Council of Turkey (Quick Support Program Code: 113S447).

\section{REFERENCES}

1. El-Bialy T, El-Shamy I, Graber TM. Growth modification of the rabbit mandible using therapeutic ultrasound: Is it possible to enhance functional appliance results? Angle Orthod 2003;73:631-9.

2. Bishara SE, Ziaja RR. Functional appliances: A review. Am J Orthod Dentofacial Orthop 1989;95:250-8.

3. Patel HP, Moseley HC, Noar JH. Cephalometric determinants of successful functional appliance therapy. Angle Orthod 2002;72:410-7.

4. Panigrahi $P$, Vineeth V. Biomechanical effects of fixed functional appliance on craniofacial structures. Angle Orthod 2009;79:668-75.

5. Owtad P, Potres Z, Shen G, Petocz P, Darendeliler MA. A histochemical study on condylar cartilage and glenoid fossa during mandibular advancement. Angle Orthod 2011;81:270-6.

6. Xiong H, Hägg U, Tang GH, Rabie AB, Robinson W. The effect of continuous bite-jumping in adult rats: A morphological study. Angle Orthod 2004;74:86-92.

7. Taira K, Iino S, Kubota T, Fukunaga T, Miyawaki S. Effects of mandibular advancement plus prohibition of lower incisor movement on mandibular growth in rats. Angle Orthod 2009;79:1095-101.

8. Rabie AB, Leung FY, Chayanupatkul A, Hägg U. The correlation 
between neovascularization and bone formation in the condyle during forward mandibular positioning. Angle Orthod 2002;72:431-8.

9. Gungor AY, Turkkahraman H, Yilmaz HH, Yariktas M. Cephalometric comparison of obstructive sleep apnea patients and healthy controls. Eur J Dent 2013;7:48-54

10. Killiany DM, Johnson ON, Johnston LE Jr. Combined cephalometric and transcranial radiography of the rat condyle. Angle Orthod 1987;57:162-7.

11. Ghafari J, Degroote C. Condylar cartilage response to continuous mandibular displacement in the rat. Angle Orthod 1986;56:49-57.

12. Rabie AB, Zhao Z, Shen G, Hägg EU, Dr O, Robinson W. Osteogenesis in the glenoid fossa in response to mandibular advancement. Am J Orthod Dentofacial Orthop 2001;119:390-400.

13. Charlier JP, Petrovic A, Herrmann-Stutzmann J. Effects of mandibular hyperpropulsion on the prechondroblastic zone of young rat condyle. Am J Orthod 1969;55:71-4.
14. Liu C, Kaneko S, Soma K. Effects of a mandibular lateral shift on the condyle and mandibular bone in growing rats. Angle Orthod 2007;77:787-93.

\begin{tabular}{|l|l|}
\hline \multicolumn{2}{|c|}{ Access this article online } \\
\hline Quick Response Code: & Website: \\
\hline & www.eurjdent.com \\
\cline { 2 - 2 } & \\
\hline
\end{tabular}

